\title{
ФОРМИРОВАНИЕ КОММУНИКАЦИОННЫХ НАВЫКОВ ПУТЕМ ВНЕДРЕНИЯ КАРТЫ РАЗВИТИЯ SOFT-SКILLS В ПРОФЕССИОНАЛЬНОМ ОБРАЗОВАНИИ ІТ-СПЕЦИАЛИСТОВ
}

\author{
Рыжкова Марина Вячеславовна1, \\ marybox@inbox.ru \\ Шефер Елизавета Олеговна², \\ syo@smartworld.team
}

Кондратьева Анастасия Александровна 3 , kondrateva_tusur@mail.ru

Соболева Екатерина Николаевна 1 , sobolek88@mail.com

${ }^{1}$ Национальный исследовательский Томский государственный университет, Россия, 634050, Томск, пр. Ленина, 36.

${ }^{2}$ Национальный исследовательский Томский политехнический университет, Россия, 634050, Томск, пр. Ленина, 30.

3 Томский государственный университет систем управления и радиоэлектроники, Россия, 634050, Томск, пр. Ленина, 40.

Рыжкова Марина Вячеславовна, доктор экономических наук, профессор кафедры экономики Института экономики и менеджмента Национального исследовательского Томского государственного университета.

Шефер Елизавета Олеговна, магистрант Школы инженерного предпринимательства Национального исследовательского Томского политехнического университета.

Кондратьева Анастасия Александровна, старший преподаватель кафедры экономики Томского государственного университета систем управления и радиоэлектроники.

Соболева Екатерина Николаевна, кандидат экономических наук, доцент кафедры экономики Института экономики и менеджмента Национального исследовательского Томского государственного университета.

Актуальность исследования заключается в том, что в современных условиях для работодателей большое значение имеет минимизация затрат на адаптацию выпускников системы высшего профессионального образования. В процессе обучения студенты приобретают знания, умения и навыки, но при этом у них формируется определенный тип поведения, препятствующий достижению качественного результата в определённый срок. Это возникает благодаря коммуникационному барьеру, появляющемуся в ходе адаптации молодого сотрудника на рабочем месте. Цель работы: выявить недостающие компетенции в профессиональном образовании IT-специалистов и разработать карту их развития в проекте «Академия Умный Мир» (томская IT-компания «Умный Мир»). Методы: анализ конкурентной среды рынка профессионального образования IT-специалистов, метод интегральных оценок для анализа акселерационных программ томских работодателей, карта компетенций. Результаты исследования потребностей работодателей и трендов в профессиональном образовании IT-специалистов позволили составить карту необходимых компетенций. Основными недостающими в образовании компетенциями стали «мягкие навыки», особенно это касается способности работать в команде. Эти компетенции являются универсальными для начинающих специалистов и выпускников вузов, а их развитие представляет собой интерес для IT-сферы 
и бизнеса. Составленная карта компетенций позволит томским IT-компаниям подбирать сотрудников и влиять на их дальнейшее профессиональное развитие, а для университетов данная карта является ориентировочным профилем выпускника, подготовка которого увеличит востребованность у работодателя. В итоге создаются условия для преодоления структурного разрыва между потребностями работодателей и профессиональным образованием IT-специалистов.

Ключевые слова: Академия «Умный Мир», IT-специалисты, soft-навыки, командное обучение, проектно-ориентированное обучение (PBL).

В современном мире диплом вуза не является гарантом последующего трудоустройства. На сайте НeadHanter соискателей в Томске по профилю программиста, а точнее молодых специалистов, в 10 раз больше, чем вакансий для них. Бизнес, а в особенности IT, не готов брать на работу специалистов без опыта.

В ходе обучения в университете студенты приобретают определённый тип поведения, когда выполняют всю работу в последний момент с удовлетворительным качеством. В следствие этого выпускники, приходя на работу, следуют этому же поведению и не могут работать систематически, выдавать качественный результат, в определённый срок. Именно поэтому компании не хотят брать специалистов сразу после вуза и требуют хотя бы минимальный опыт.

Это связано с тем, что для любой IT-компании основной риск - нанять неквалифицированного специалиста. Первые 4-6 месяцев компания тратит на него множество ресурсов - выделяет наставника, обучает его под себя нужным инструментам, погружает в корпоративную культуру. Все это время молодой специалист будет только включаться в работу, проходить этап адаптации. И по факту в это время он не приносит прибыль для компании, т. е. на него тратится ресурсов больше, чем он выполняет полезной работы.

Вследствие этого перед IT-компаниями встает вопрос о качественной подготовке специалистов, взаимодействии с высшими и профессиональными учебными заведениями в соответствии с изменениями в IT-сфере.

Проект «Академия Умный Мир» - это социальный некоммерческий проект, который позволяет молодым специалистам без опыта работы попасть в IT-сферу. Академия была создана в рамках компании «Умный Мир» для найма таких специалистов.

После адаптационного периода сотрудника возможны два негативных варианта развития событий:

- сотрудник может не подойти компании в связи с неспособностью перенять технические или личностные качества в течение адаптационного периода; рентам.

- сотрудник может сам уйти после адаптационного периода, например, к конку-

Каждый раз нанимая сотрудника в компанию через биржу труда, компания находится в неопределенности, поскольку не знает, как человек покажет себя, сможет ли он быстро обучиться и адаптироваться на новом месте. Ответственность HR-отдела не включает адаптационный период и заканчивается ровно в тот момент, когда сотрудник официально приступает к работе.

Вышеописанные проблемы, с которыми сталкивается компания «Умный Мир», и подтолкнули руководство к созданию такого проекта.

Цель проекта - за три месяца подготовить специалистов, которые под руководством тимлида смогут сразу начать работать в компании и разрабатывать проект.

В течение этих трех месяцев студенты Академии работают над своими профессиональными и личностными навыками под предводительством наставников. Наставники это практикующие специалисты компании или сотрудники извне, которые не являются 
преподавателями, но работают в той же области, которой обучают молодых ребят. Это позволяет избежать теоретических знаний, которые не применимы на практике.

В работе был проведен конкурентный анализ для того, чтобы определить сильные стороны проекта «Академия Умный Мир» и других томских компаний, реализующих подобные проекты. Этот анализ дает понимание о том, как подобные компании подготавливают IT-специалистов. Результаты конкурентного анализа отражены в табл. 1.

Таблица 1. Конкурентный анализ

Table 1. Competitive analysis

\begin{tabular}{|c|c|c|c|}
\hline $\begin{array}{l}\text { Наименование } \\
\text { программы } \\
\text { Program name }\end{array}$ & $\begin{array}{l}\text { Цена обучения } \\
\text { Training price }\end{array}$ & $\begin{array}{l}\text { Плюсы } \\
\text { Pros }\end{array}$ & $\begin{array}{l}\text { Минусы } \\
\text { Minuses }\end{array}$ \\
\hline \multirow{8}{*}{$\begin{array}{l}\text { Академия } \\
\text { «Умный Мир» } \\
\text { «Smart World» } \\
\text { Academy [1] }\end{array}$} & \multirow{8}{*}{0} & Бесплатно/Free & $\begin{array}{l}\text { Не сертифицирована } \\
\text { Not certified }\end{array}$ \\
\hline & & $\begin{array}{l}\text { Командное обучение } \\
\text { Team training }\end{array}$ & $\begin{array}{l}\text { Слабая рекламная кампания } \\
\text { Weak advertising campaign }\end{array}$ \\
\hline & & $\begin{array}{l}\text { Сотрудничество с крупными ву- } \\
\text { зами (ТГУ, ТПУ, ТУСУР) } \\
\text { Cooperation with large universities } \\
\text { (TSU, TPU, Tomsk State Universi- } \\
\text { ty of Control Systems and Radioe- } \\
\text { lectronics) }\end{array}$ & \multirow{6}{*}{$\begin{array}{l}\text { Малая известность } \\
\text { Little fame }\end{array}$} \\
\hline & & $\begin{array}{l}\text { Проектная разработка, погруже- } \\
\text { ние в работу } \\
\text { Design development, immersion in } \\
\text { work }\end{array}$ & \\
\hline & & $\begin{array}{l}\text { Уникальный тренинг на развитие } \\
\text { личностных навыков } \\
\text { Unique training for development of } \\
\text { personal skills }\end{array}$ & \\
\hline & & $\begin{array}{l}\text { Лекции от экспертов } \\
\text { Lectures from experts }\end{array}$ & \\
\hline & & $\begin{array}{l}\text { Трудоустройство по окончании } \\
\text { Employment after graduation }\end{array}$ & \\
\hline & & $\begin{array}{l}\text { Обучение очно-заочное } \\
\text { Part-time education }\end{array}$ & \\
\hline \multirow{4}{*}{$\begin{array}{l}\text { Rubius } \\
\text { Academy [2] }\end{array}$} & \multirow{4}{*}{$\begin{array}{l}10500 \mathrm{p} . / \mathrm{Mec} . \\
\text { (rubles/month) }\end{array}$} & $\begin{array}{l}\text { Популярность, все знают о ней } \\
\text { Popularity, everyone knows about it }\end{array}$ & $\begin{array}{l}\text { Нет трудоустройства } \\
\text { No employment }\end{array}$ \\
\hline & & Лицензирована/Licensed & $\begin{array}{l}\text { Отдали сертификат и забыли } \\
\text { о студентах } \\
\text { Gave the certificate and forgot } \\
\text { about the students }\end{array}$ \\
\hline & & $\begin{array}{l}\text { Хорошо выстроены } \\
\text { позиционирование и реклама } \\
\text { Well positioning and advertising } \\
\end{array}$ & \multirow{2}{*}{$\begin{array}{l}\text { Нет проектной разработки } \\
\text { No design development }\end{array}$} \\
\hline & & $\begin{array}{l}\text { Дополнительные курсы - ан- } \\
\text { глийский } \\
\text { Additional courses - English }\end{array}$ & \\
\hline \multirow[t]{3}{*}{$\begin{array}{l}\text { Fullstack } \\
\text { Development } \\
{[3]}\end{array}$} & \multirow[t]{3}{*}{0} & $\begin{array}{l}\text { Простота в обучении и трудо- } \\
\text { устройстве } \\
\text { Ease of learning and employment }\end{array}$ & $\begin{array}{l}\text { Низкая конверсия тех, кто } \\
\text { доходит до конца } \\
\text { Low conversion of those who } \\
\text { reach the end }\end{array}$ \\
\hline & & $\begin{array}{l}\text { Все удаленно } \\
\text { Everything remotely }\end{array}$ & $\begin{array}{l}\text { Нет наставничества } \\
\text { No mentoring }\end{array}$ \\
\hline & & Нет ограничений по времени & Слабо проработанный сайт \\
\hline
\end{tabular}




\begin{tabular}{|c|c|c|c|}
\hline & & $\begin{array}{l}\text { обучения } \\
\text { No time limit for training }\end{array}$ & $\begin{array}{l}\text { для IT-компании } \\
\text { Poorly designed website for an } \\
\text { IT company }\end{array}$ \\
\hline & & $\begin{array}{l}\text { Международная организация } \\
\text { International organization }\end{array}$ & $\begin{array}{l}\text { Система продаж плохо вы- } \\
\text { строена } \\
\text { Sales system is poorly built }\end{array}$ \\
\hline \multirow{4}{*}{$\begin{array}{l}\text { Академия } \\
\text { «Шаг» } \\
\text { Academy } \\
\text { «Step» } \\
{[4]}\end{array}$} & \multirow{4}{*}{$\begin{array}{c}5000 \text { p./Mec } \\
\text { (rubles/month) }\end{array}$} & $\begin{array}{l}\text { Сотрудничают с кадровыми } \\
\text { агентствами } \\
\text { Collaborate with recruiting } \\
\text { agencies }\end{array}$ & \multirow{4}{*}{$\begin{array}{l}\text { Не рекламируются, о них ни- } \\
\text { чего не известно } \\
\text { Not advertised, nothing is } \\
\text { known about them }\end{array}$} \\
\hline & & $\begin{array}{l}\text { Вечерние занятия } \\
\text { Evening classes }\end{array}$ & \\
\hline & & $\begin{array}{l}\text { Обучают детей и школьников } \\
\text { Teach children and schoolchildren }\end{array}$ & \\
\hline & & $\begin{array}{l}\text { Есть команда, которая занимает- } \\
\text { ся именно обучением } \\
\text { There is a team that deals specifi- } \\
\text { cally with training }\end{array}$ & \\
\hline \multirow[b]{2}{*}{ KODE [5] } & \multirow{2}{*}{$\begin{array}{l}\text { Есть платные и } \\
\text { бесплатные кур- } \\
\text { сы и стажировки. } \\
\text { Точная цена не- } \\
\text { известна } \\
\text { There are paid and } \\
\text { free courses and } \\
\text { internships. The } \\
\text { exact price is un- } \\
\text { known }\end{array}$} & \multirow[b]{2}{*}{$\begin{array}{l}\text { Есть офис в Калининграде } \\
\text { There is an office in Kaliningrad }\end{array}$} & $\begin{array}{l}\text { Невозможно найти стоимость } \\
\text { Can't find the cost }\end{array}$ \\
\hline & & & $\begin{array}{l}\text { Узкая направленность } \\
\text { Narrow focus }\end{array}$ \\
\hline
\end{tabular}

В табл. 2 каждую томскую акселерационную программу сравнили по ключевым показателям, которые имеют важное значение для пользователей. К этим показателям относятся:

- дешевизна;

- сложность входа;

- удаленный формат;

- трудоустройство;

- практический опыт;

- известность;

- сертификаты.

Таблица 2. Интегральная оценка

Table 2. Integral assessment

\begin{tabular}{|c|c|c|c|c|c|c|}
\hline $\begin{array}{l}\text { Параметр } \\
\text { Parameter }\end{array}$ & $\begin{array}{c}\text { Весовой } \\
\text { коэффициент } \\
\text { Weight } \\
\text { coefficient }\end{array}$ & $\begin{array}{c}\text { Академия «Умный } \\
\text { Мир» } \\
\text { «Smart World» Acad- } \\
\text { emy }\end{array}$ & $\begin{array}{l}\text { Rubius } \\
\text { Academy }\end{array}$ & $\begin{array}{c}\text { Fullstack } \\
\text { Development }\end{array}$ & $\begin{array}{c}\text { Академия } \\
\text { «Шаг» } \\
\text { «Step» } \\
\text { Academy }\end{array}$ & $\stackrel{1}{\hat{0}}$ \\
\hline $\begin{array}{l}\text { Дешевизна } \\
\text { Cheapness }\end{array}$ & 5 & 5 & 2 & 5 & 3 & 4 \\
\hline $\begin{array}{l}\text { Сложность входа } \\
\text { Difficulty of entry }\end{array}$ & 3 & 4 & 5 & 5 & 5 & 3 \\
\hline $\begin{array}{l}\text { Удаленный формат } \\
\text { Remote format }\end{array}$ & 3 & 4 & 2 & 5 & 1 & 1 \\
\hline Трудоустройство & 4 & 5 & 2 & 4 & 4 & 4 \\
\hline
\end{tabular}




\begin{tabular}{|l|c|c|c|c|c|c|}
\hline Employment & & & & & \\
\hline $\begin{array}{l}\text { Практический опыт } \\
\text { Practical ехреrience }\end{array}$ & 2 & 5 & 4 & 1 & 1 & 3 \\
\hline $\begin{array}{l}\text { Известность } \\
\text { Notoriety }\end{array}$ & 4 & 3 & 5 & 2 & 5 & 4 \\
\hline $\begin{array}{l}\text { Сертификаты } \\
\text { Сеrtificates }\end{array}$ & 2 & 1 & 4 & 1 & 5 & 1 \\
\hline $\begin{array}{l}\text { Интегральная оценка } \\
\text { Integral assessment }\end{array}$ & 93 & 75 & 83 & 81 & 72 \\
\hline
\end{tabular}

Проведенный конкурентный анализ и итоги интегральной оценки показали значительный разрыв между проектом «Академия Умный Мир» и другими программами томских IT-компаний.

Рекомендации, которые можно выделить из сравнительного анализа:

1) продукт «Академия» проигрывает в известности и популярности нескольким другим продуктам;

2) академия не имеет образовательной лицензии;

3) необходимо уделить внимание не только качественному развитию продукта, но и бренду;

4) перейти на PUSH-стратегию в маркетинге;

5) использовать другие каналы коммуникации с аудиторией;

6) выйти за пределы Томска.

Далее автор приводит тренды IT-направлений, которые были выявлены в профессиональном образовании.

Командно-ориентированное образование получило всеобщее признание после появления стартап-акселераторов. Такие акселераторы, как Y Combinator и 500 Startups, считают появление успешных команд с правильными навыками ключевым результатом работы их программ.

В табл. 3 отражены преимущества и недостатки командного обучения ITспециалистов.

\section{Таблища 3. Преимущества и недостатки командного обучения Table 3. Advantages and disadvantages of team training}

\begin{tabular}{|c|c|}
\hline Преимущества/Advantages & Недостатки/Disadvantages \\
\hline $\begin{array}{l}\text { 1. Групповой формат включает слушателей в рабо- } \\
\text { ту и не оставляет места для пассивного слушания } \\
\text { The group format involves participants in the work } \\
\text { and leaves no room for passive listening } \\
\text { 2. Преподаватель может подстроиться под потреб- } \\
\text { ности группы и сконцентрироваться только на } \\
\text { тех аспектах, которые остались непонятными } \\
\text { именно в данной группе } \\
\text { The teacher can adapt to the needs of the group and } \\
\text { concentrate only on those aspects that remained in- } \\
\text { comprehensible in this particular group } \\
\text { Может не тратить время на объяснение материа- } \\
\text { ла, который слушатели смогли освоить самостоя- } \\
\text { тельно } \\
\text { May not waste time on explaining the material that } \\
\text { the listeners were able to master on their own }\end{array}$ & $\begin{array}{l}\text { 1. Организация групповой динамики может } \\
\text { потребовать от преподавателя/наставника } \\
\text { дополнительных навыков } \\
\text { Organization of group dynamics may require ad- } \\
\text { ditional skills from the teacher/mentor } \\
\text { 2. Необходимо подготовить источники, по ко- } \\
\text { торым слушатели смогут самостоятельно } \\
\text { ознакомиться с темой } \\
\text { It is necessary to prepare sources by which the } \\
\text { listeners can independently familiarize them- } \\
\text { selves with the topic } \\
\text { Много ответственности на студентах - зада- } \\
\text { ния может быть выполнено менее эффектив- } \\
\text { но, если слушатели не читают дополнитель- } \\
\text { ную литературу } \\
\text { А lot of responsibility on students - tasks can be } \\
\text { completed less efficiently if students do not read } \\
\text { additional literature }\end{array}$ \\
\hline
\end{tabular}


Данные факты были выяснены и взяты под контроль в ходе работы акселерационной программы «Академия Умный Мир».

Глобальные изменения в отношении к работе и образу жизни означают растущий спрос на новые индивидуальные и коллективные компетенции [6].

Общепринятое понимание компетенций будущего включает:

1. Различные профессиональные («жесткие», hard) компетенции и знания, связанные с изменениями в технологиях и организации работы.

2. «Мягкие» надпрофессиональные компетенции и универсальные знания, которые можно применять во всех профессиях, социальных и личных ситуациях (включая те, которые связаны с волной технологической трансформации), такие как [7]:

- коммуникативные навыки;

- умение эффективно работать в команде;

- способность проводить обучение и консультирование;

- способность к самостоятельному обучению новым методам исследования;

- использование знаний правовых и этических норм при оценке последствий своей профессиональной деятельности [8].

Soft-навыки позволяют начинающей команде при правильно поставленной задаче работать не менее эффективно, чем более опытные сотрудники. Такую команду после прохождения обучения можно сразу привлекать к коммерческому проекту компании, благодаря тому, что Академия имитирует работу в компании по тем же принципам и ценностям. У команды не возникает периода адаптации, поскольку она уже в течении трех месяцев работала в таком же режиме.

Тенденция современной системы образования, основанная на воспитании саморазвивающейся личности, предполагает учет индивидуальных особенностей, потребностей, возможностей обучающихся. Выступая как субъект педагогической деятельности, студент должен быть ориентирован на свободное развитие личности, творческую инициативу, самостоятельность, конкурентоспособность, профессиональную мобильность, что требует качествен н о нового подхода к формированию будущего специалиста.

Требования, предъявляемые обществом к квалификации современного специалиста-информатика, приводят к достаточно жесткой конкуренции в этом секторе рынка труда. Работодатели отдают предпочтение тем молодым специалистам, которые не только обладают обширными знаниями и навыками в области информационных технологий, но и умеют быть «командными игроками».

Понятие «проект» (от лат. progectus - выдвигать вперед) означает разработку некой идеи, детального плана какого-либо продукта [9].

К требованиям, предъявляемым к проектному обучению, относятся:

- значимая в теоретическом, техническом и исследовательском плане задача, решение которой приведет к созданию определенного продукта;

- разрабатываемая идея должна отличаться своей новизной;

- результаты проекта должны быть представлены руководству проекта и компании;

- как правило, достаточно хорошо разработанный проект должен иметь возможность продолжения для коммерциализации [10].

В табл. 4 представлены этапы разработки по методике проектноориентированного обучения, используемого в Академии «Умный Мир». Эти этапы выстроены таким образом, чтобы максимально погрузить начинающих специалистов без опыта в разработку продукта. 
Таблица 4. Этапы проектной разработки в Академии «Умный Мир» Table 4. Stages of project development in «Smart World» Academy

\begin{tabular}{|c|c|c|}
\hline Задача/Task & $\begin{array}{l}\text { Методы и инструменты } \\
\text { Methods and tools }\end{array}$ & Результат/Result \\
\hline \multicolumn{3}{|c|}{$\begin{array}{l}\text { Этап 1. Погружение в проект. Выяснение бизнес-задач заказчика } \\
\text { Stage 1. Immersion in the project. Clarification of the customer business objectives }\end{array}$} \\
\hline $\begin{array}{l}\text { Интервью с заказчиком } \\
\text { Customer interview }\end{array}$ & \begin{tabular}{|ll} 
1. & Решенческое интервью \\
2. & $\begin{array}{l}\text { Сесіsional interview } \\
\text { Составление брифа } \\
\text { Drawing up a brief }\end{array}$ \\
\end{tabular} & $\begin{array}{l}\text { Оформленный бриф } \\
\text { Formalized brief }\end{array}$ \\
\hline $\begin{array}{l}\text { Паспорт проекта } \\
\text { Project passport }\end{array}$ & $\begin{array}{l}\text { Методичка по составлению } \\
\text { паспорта проекта } \\
\text { Guidelines for drawing up a pro- } \\
\text { ject passport }\end{array}$ & $\begin{array}{l}\text { Документ, который описывает назначе- } \\
\text { ние, функционал, концептуальную модель } \\
\text { продукта } \\
\text { A document that describes the purpose, func- } \\
\text { tionality, conceptual model of the product }\end{array}$ \\
\hline \multicolumn{3}{|c|}{$\begin{array}{l}\text { Этап 2. Разработка проекта. Построение внутренней архитектуры } \\
\text { Stage 2. Development of the project. Building internal architecture }\end{array}$} \\
\hline $\begin{array}{l}\text { Фронтенд часть проекта } \\
\text { Front-end part of the project }\end{array}$ & HTML/CSS & $\begin{array}{l}\text { Готовая пользовательская часть интер- } \\
\text { фейса } \\
\text { Ready user interface part }\end{array}$ \\
\hline $\begin{array}{l}\text { Бэкенд часть проекта } \\
\text { Backend part of the project }\end{array}$ & PHP, Laravel & $\begin{array}{l}\text { Построенная база данных для хранения и } \\
\text { отправки информации } \\
\text { Built database for storing and sending infor- } \\
\text { mation }\end{array}$ \\
\hline $\begin{array}{l}\text { Интеграция бэкенд и } \\
\text { фронтенд частей } \\
\text { Integration of backend and } \\
\text { frontend parts }\end{array}$ & API & $\begin{array}{l}\text { Кликабельный прототип продукта } \\
\text { Clickable product prototype }\end{array}$ \\
\hline \multicolumn{3}{|c|}{$\begin{array}{l}\text { Этап 3. Тестирование } \\
\text { Stage 3. Testing } \\
\end{array}$} \\
\hline $\begin{array}{l}\text { Поиск и исправление ба- } \\
\text { гов продукта } \\
\text { Finding and fixing product } \\
\text { bugs }\end{array}$ & $\begin{array}{ll}\text { 1. } & \text { Тест-кейсы/Test cases } \\
\text { 2. } & \text { Ручное тестирование } \\
& \text { Manual testing } \\
\text { 3. } & \text { Автотесты/Autotests } \\
\end{array}$ & $\begin{array}{l}\text { Документация с указанными ошибками } \\
\text { проекта для разработчиков } \\
\text { Developer documentation with specified pro- } \\
\text { ject errors }\end{array}$ \\
\hline $\begin{array}{l}\text { Пользовательское тести- } \\
\text { рование User testing }\end{array}$ & UX / UI & $\begin{array}{l}\text { Доработка прототипа Finalization of the } \\
\text { prototype }\end{array}$ \\
\hline \multicolumn{3}{|c|}{$\begin{array}{l}\text { Этап 4. Защита проекта } \\
\text { Stage 4. Project protection }\end{array}$} \\
\hline $\begin{array}{l}\text { Представление результа- } \\
\text { тов } \\
\text { Presentation of results } \\
\end{array}$ & $\begin{array}{l}\text { Навыки самопрезентации } \\
\text { Skills of self-presentation }\end{array}$ & $\begin{array}{l}\text { Презентация, прототип проекта, код про- } \\
\text { екта } \\
\text { Presentation, project prototype, project code }\end{array}$ \\
\hline
\end{tabular}

Для того чтобы это проследить, мы рассмотрим технологические аспекты работы над проектом на каждом этапе:

- на подготовительном этапе определяются цели и задачи проекта. Наставник при этом помогает разрабатывать структуру проекта, но не выполняет задания за обучающихся;

- этап работы над проектом. Студенты осуществляют основные действия по разработке проекта. Роль наставника заключается в их консультировании, стимулировании их деятельности, поощрении, контроле за ходом выполнения проекта и обеспечении непрерывной обратной связи для достижения успешных результатов студентов;

- завершающим этапом является представление (защита) проекта. Готовые результаты должны быть оформлены согласно формам отчетности. Наставник корректи- 
рует отчет, организует экспертизу результатов, оценивает вклад каждого из участников в проект и результаты проекта в целом.

Отметим, что при выполнении работ у студентов не могут не возникнуть некоторые сложности. Чаще всего они связаны с постановкой ведущих и текущих целей и задач, с поиском решения, сопоставлении полученного результата и требуемого, оценкой собственной деятельности [11, 12].

Однако метод проектов имеет свои недостатки:

- из-за индивидуальных особенностей каждого из участников степень их ответственности за ход и результаты работы значительно отличается;

- снижается возможность получения полного опыта каждым участником на всех этапах проекта из-за выполнения ими разных ролей;

- возможность некоторыми студентами решения своих задач в процессе выполнения проекта за счет более инициативных участников группы;

- возникновение сложностей при оценке вклада каждого члена группы в командный результат [13].

Для того чтобы участник проекта, а в дальнейшем сотрудник компании имел мотивацию расти и развиваться дальше не только в профессиональных навыках, но и в личностных, поскольку именно развитие последних позволяет сотруднику в конечном счете занять управляющую позицию, нами была разработана карта компетенций сотрудника. Описание каждого уровня карты отражено в табл. 5.

Таблища 5. Описание уровней карты компетенций сотрудника Table 5. Description of employee's competence map levels

\begin{tabular}{|c|c|c|c|c|}
\hline \multirow{2}{*}{ Soft skills } & \multicolumn{4}{|c|}{ Уровень/Level } \\
\hline & $0(0)$ & $1(0.5)$ & $2(1)$ & $3(2)$ \\
\hline $\begin{array}{l}\text { Ответственность } \\
\text { Responsibility }\end{array}$ & $\begin{array}{l}\text { Избегает того, } \\
\text { чтобы брать на } \\
\text { себя ответствен- } \\
\text { ность } \\
\text { Avoids taking } \\
\text { responsibility }\end{array}$ & $\begin{array}{l}\text { Иногда берет на себя } \\
\text { обязательства, но } \\
\text { редко соблюдает } \\
\text { сроки их выполнения } \\
\text { Sometimes takes on } \\
\text { obligations, but rarely } \\
\text { meets the deadlines } \\
\text { for their fulfillment }\end{array}$ & $\begin{array}{l}\text { Берет на себя } \\
\text { обязательства, } \\
\text { часто срываются } \\
\text { сроки их выпол- } \\
\text { нения } \\
\text { Takes on obliga- } \\
\text { tions, often the } \\
\text { deadlines for their } \\
\text { fulfillment are } \\
\text { missed }\end{array}$ & $\begin{array}{l}\text { Берет на себя } \\
\text { обязательства, } \\
\text { соблюдает сроки } \\
\text { выполнения } \\
\text { Assumes } \\
\text { obligations, } \\
\text { adheres to } \\
\text { deadlines }\end{array}$ \\
\hline $\begin{array}{l}\text { Коммуникативность } \\
\text { Communicativeness }\end{array}$ & $\begin{array}{l}\text { Не коммуникати- } \\
\text { вен, замкнут, на } \\
\text { контакт не идёт. } \\
\text { Неграмотная речь } \\
\text { Легко идет на } \\
\text { контакт с уже зна- } \\
\text { комыми людьми. } \\
\text { В общении не ги- } \\
\text { бок } \\
\text { Not } \\
\text { communicative, } \\
\text { closed, does not } \\
\text { make contact. Gib- } \\
\text { berish } \\
\text { Easily makes con- } \\
\text { tact with already } \\
\text { familiar people. He } \\
\text { is not flexible in }\end{array}$ & $\begin{array}{l}\text { Коммуникативные } \\
\text { навыки развиты сла- } \\
\text { бо, но идет на кон- } \\
\text { такт с людьми. При } \\
\text { общении соглашает- } \\
\text { ся во всем с собесед- } \\
\text { ником, не умеет до- } \\
\text { нести точку зрения и } \\
\text { аргументировать } \\
\text { позицию Communi- } \\
\text { cation skills are poorly } \\
\text { developed, but it } \\
\text { makes contact with } \\
\text { people. When com- } \\
\text { municating, he agrees } \\
\text { with the interlocutor in } \\
\text { everything, does not } \\
\text { know how to convey }\end{array}$ & $\begin{array}{l}\text { Легко идёт на } \\
\text { контакт с незна- } \\
\text { комыми людьми. } \\
\text { В общении про- } \\
\text { являет гибкость. } \\
\text { Ораторские спо- } \\
\text { собности нуж- } \\
\text { даются в разви- } \\
\text { тии } \\
\text { Contact with } \\
\text { strangers is easy. } \\
\text { Shows flexibility } \\
\text { in communica- } \\
\text { tion. Speaking } \\
\text { skills need devel- } \\
\text { opment }\end{array}$ & $\begin{array}{l}\text { Отличные ора- } \\
\text { торские способ- } \\
\text { ности. Грамотная } \\
\text { устная и пись- } \\
\text { менная речь. } \\
\text { Объясняет корот- } \\
\text { ко и так, что по- } \\
\text { нятно без каких- } \\
\text { либо вопросов } \\
\text { Excellent public } \\
\text { speaking skills. } \\
\text { Correct oral and } \\
\text { written language. } \\
\text { Explains briefly } \\
\text { and in a way that is } \\
\text { understandable } \\
\text { without any ques- } \\
\text { tions }\end{array}$ \\
\hline
\end{tabular}




\begin{tabular}{|c|c|c|c|c|}
\hline & communication & $\begin{array}{l}\text { the point of view and } \\
\text { argue the position }\end{array}$ & & \\
\hline $\begin{array}{l}\text { Самостоятельность } \\
\text { в принятии реше- } \\
\text { ний } \\
\text { Independence in } \\
\text { decision making }\end{array}$ & $\begin{array}{l}\text { Не выявляет про- } \\
\text { блему и не пыта- } \\
\text { ется ее решить, } \\
\text { возлагает это на } \\
\text { плечи руководи- } \\
\text { теля или коллег } \\
\text { Does not identify } \\
\text { the problem and } \\
\text { does not try to } \\
\text { solve it, leaves it on } \\
\text { the shoulders of the } \\
\text { manager or col- } \\
\text { leagues }\end{array}$ & $\begin{array}{l}\text { Выявляет проблему } \\
\text { самостоятельно, } \\
\text { необходима помощь } \\
\text { окружающих его } \\
\text { коллег и/или руково- } \\
\text { дителей в генерации } \\
\text { идей, аналитике и } \\
\text { принятии решения } \\
\text { Identifies the problem } \\
\text { on his own, he needs } \\
\text { help from colleagues } \\
\text { and/or managers } \\
\text { around him in generat- } \\
\text { ing ideas, analytics } \\
\text { and decision-making }\end{array}$ & $\begin{array}{l}\text { Самостоятельно } \\
\text { выявляет про- } \\
\text { блему, ищет ин- } \\
\text { формацию по } \\
\text { решению, пред- } \\
\text { лагает варианты, } \\
\text { принятие реше- } \\
\text { ние происходит } \\
\text { под контролем } \\
\text { руководителя } \\
\text { Identifies the } \\
\text { problem on his } \\
\text { own, looks for } \\
\text { information on } \\
\text { the solution, of- } \\
\text { fers options, the } \\
\text { decision is made } \\
\text { under the supervi- } \\
\text { sion of the head }\end{array}$ & $\begin{array}{l}\text { Самостоятельно } \\
\text { выявляет пробле- } \\
\text { му, собирает ин- } \\
\text { формацию и вы- } \\
\text { бирает оптималь- } \\
\text { ное решение } \\
\text { Identifies the prob- } \\
\text { lem independently, } \\
\text { collects infor- } \\
\text { mation and choos- } \\
\text { es the best solution }\end{array}$ \\
\hline $\begin{array}{l}\text { Инициативность } \\
\text { Initiative }\end{array}$ & $\begin{array}{l}\text { Равнодушен к } \\
\text { происходящему } \\
\text { вокруг, не прояв- } \\
\text { ляет инициативу } \\
\text { Indifferent to what } \\
\text { is happening } \\
\text { around, does not } \\
\text { show initiative }\end{array}$ & $\begin{array}{l}\text { Иногда высказывает } \\
\text { предложения, но не } \\
\text { участвует в их реа- } \\
\text { лизации } \\
\text { Sometimes makes } \\
\text { suggestions, but does } \\
\text { not participate in their } \\
\text { implementation }\end{array}$ & $\begin{array}{l}\text { Часто предлагает } \\
\text { идеи или пути } \\
\text { решения, иногда } \\
\text { участвует в их } \\
\text { реализации } \\
\text { Often offers ideas } \\
\text { or solutions, } \\
\text { sometimes partic- } \\
\text { ipates in their } \\
\text { implementation }\end{array}$ & $\begin{array}{l}\text { Способен видеть, } \\
\text { что нужно ме- } \\
\text { нять, предлагает } \\
\text { изменения, ини- } \\
\text { циирует их, при- } \\
\text { нимает активное } \\
\text { участие в реали- } \\
\text { зации } \\
\text { Able to see what } \\
\text { needs to be } \\
\text { changed, proposes } \\
\text { changes, initiates } \\
\text { them, takes active } \\
\text { part in implemen- } \\
\text { tation }\end{array}$ \\
\hline $\begin{array}{l}\text { Способность рабо- } \\
\text { тать в команде } \\
\text { Ability to work in a } \\
\text { team }\end{array}$ & $\begin{array}{l}\text { Не способствует } \\
\text { возникновению } \\
\text { доверительной } \\
\text { атмосферы/не } \\
\text { умеет оценить } \\
\text { профессиональный } \\
\text { опыт коллег/не } \\
\text { привлекает других } \\
\text { к решению про- } \\
\text { блем } \\
\text { Does not foster a } \\
\text { trusting atmos- } \\
\text { phere/does not } \\
\text { know how to eval- } \\
\text { uate the profession- } \\
\text { al experience of } \\
\text { colleagues/does not } \\
\text { involve others in } \\
\text { solving problems }\end{array}$ & $\begin{array}{l}\text { Способствует воз- } \\
\text { никновению довери- } \\
\text { тельной атмосферы в } \\
\text { команде, не умеет } \\
\text { привлекать других } \\
\text { сотрудников к ко- } \\
\text { мандной работе Pro- } \\
\text { motes the creation of a } \\
\text { trusting atmosphere in } \\
\text { the team, does not } \\
\text { know how to involve } \\
\text { other employees in } \\
\text { team work }\end{array}$ & $\begin{array}{l}\text { Способствует } \\
\text { возникновению } \\
\text { доверительной } \\
\text { атмосферы, уме- } \\
\text { ет привлекать } \\
\text { сотрудников к } \\
\text { командной рабо- } \\
\text { те } \\
\text { Promotes the cre- } \\
\text { ation of a trusting } \\
\text { atmosphere, } \\
\text { knows how to } \\
\text { involve employ- } \\
\text { ees in teamwork }\end{array}$ & $\begin{array}{l}\text { Способен собрать } \\
\text { людей в команду, } \\
\text { оценить потенци- } \\
\text { ал команды и по- } \\
\text { могать обмени- } \\
\text { ваться опытом } \\
\text { Able to gather } \\
\text { people into a team, } \\
\text { assess the potential } \\
\text { of the team and } \\
\text { help share experi- } \\
\text { ences }\end{array}$ \\
\hline
\end{tabular}

В карте приведены несколько soft-компетенций и их описание, чтобы сотрудник понимал, в какую сторону необходимо расти. Однако качественных показателей недо- 
статочно, поэтому каждому уровню была присвоена оценка. Количество уровней может изменять в зависимости с укладом той или иной IT-компании. В табл. 6 отражены показатели, которые оценивают каждый уровень. После того как сотрудник и старший специалист согласуют оценку по каждой компетенции, сотрудник будет занесен в тот или иной столбец в соответствии с уровнем развития.

таблица 6. Оценочные показатели компетенций

Table 6. Assessment indicators of competencies

\begin{tabular}{|l|c|c|c|c|c|c|}
\hline \multicolumn{1}{|c|}{ Личные качества/Personal qualities } & $\begin{array}{c}\text { Junior } \\
\text { Младший }\end{array}$ & $\begin{array}{c}\text { Junior+ } \\
\text { Младший+ }\end{array}$ & $\begin{array}{c}\text { Middle } \\
\text { Средний }\end{array}$ & $\begin{array}{c}\text { Middle+ } \\
\text { Средний+ }\end{array}$ & $\begin{array}{c}\text { Senior } \\
\text { Старший }\end{array}$ & $\begin{array}{c}\text { Expert } \\
\text { Эксперт }\end{array}$ \\
\hline Ответственность/Responsibility & 1 & 1 & 1,5 & 1,5 & 2 & 2 \\
\hline $\begin{array}{l}\text { Коммуникативность } \\
\text { Соmтunicativeness }\end{array}$ & 1 & 1 & 1,5 & 1,5 & 2 & 2 \\
\hline $\begin{array}{l}\text { Самостоятельность в принятии решений } \\
\text { Independence in decision таking }\end{array}$ & 0,5 & 0,5 & 1 & 1,5 & 2 & 2 \\
\hline Инициативность/Initiative & 0,5 & 0,5 & 1 & 1 & 1,5 & 2 \\
\hline $\begin{array}{l}\text { Способность работать в команде } \\
\text { Аbility tо work in а tеат }\end{array}$ & 1 & 1 & 2 & 2 & 2 & 2 \\
\hline Среднеe/Average & 0,6 & 0,8 & 1,4 & 1,5 & 1,8 & 2 \\
\hline
\end{tabular}

Для того чтобы представить карту в визуальном формате, произведем оценку специалиста, например, уровня Middle. Оценка отражена в табл. 7. Каждый участник оценивает сначала свои компетенции самостоятельно, а затем совместно с руководителем или трекером проекта «Академия Умный Мир». Трекер еженедельно слушает отчет каждого участника о проведенной работе, поэтому может оценить навыки студентов.

Таблица 7. Пример оценки компетенций

Table 7. Example of competency assessment

\begin{tabular}{|l|c|}
\hline Личные качества/Personal qualities & Балл/Score \\
\hline Ответственность/Responsibility & 1,5 \\
\hline Коммуникативность/Communicativeness & 1,5 \\
\hline Самостоятельность в принятии решений/Independence in decision making & 1,5 \\
\hline Инициативность/Initiative & 1,5 \\
\hline Способность работать в команде/Ability to work in a team & 1 \\
\hline Среднеe/Average & 1,3864 \\
\hline
\end{tabular}

Диаграмма компетенций отражена на рисунке.

Разработанная карта компетенций будет применяться на нескольких этапах проекта «Академия Умный Мир»:

1. При прохождении входного тестирования. Необходимо определить минимальный уровень развития soft-навыков у участников проекта при поступлении на проект. Затем необходимо разработать ситуационные кейсы, решение которых позволит оценить уровень навыков.

2. Перед началом работы над командным проектом. Для развития soft-навыков к компании разработан A.C.G.-тренинг. Тренинг проводится в формате настольной игры с ролевым участием ведущего и дает эффект «быстрого опыта». Настольная игра моделирует процесс разработки программного обеспечения. В ее основе лежат гибкие методологии, в частности Agile и основные принципы методологии Scrum. 


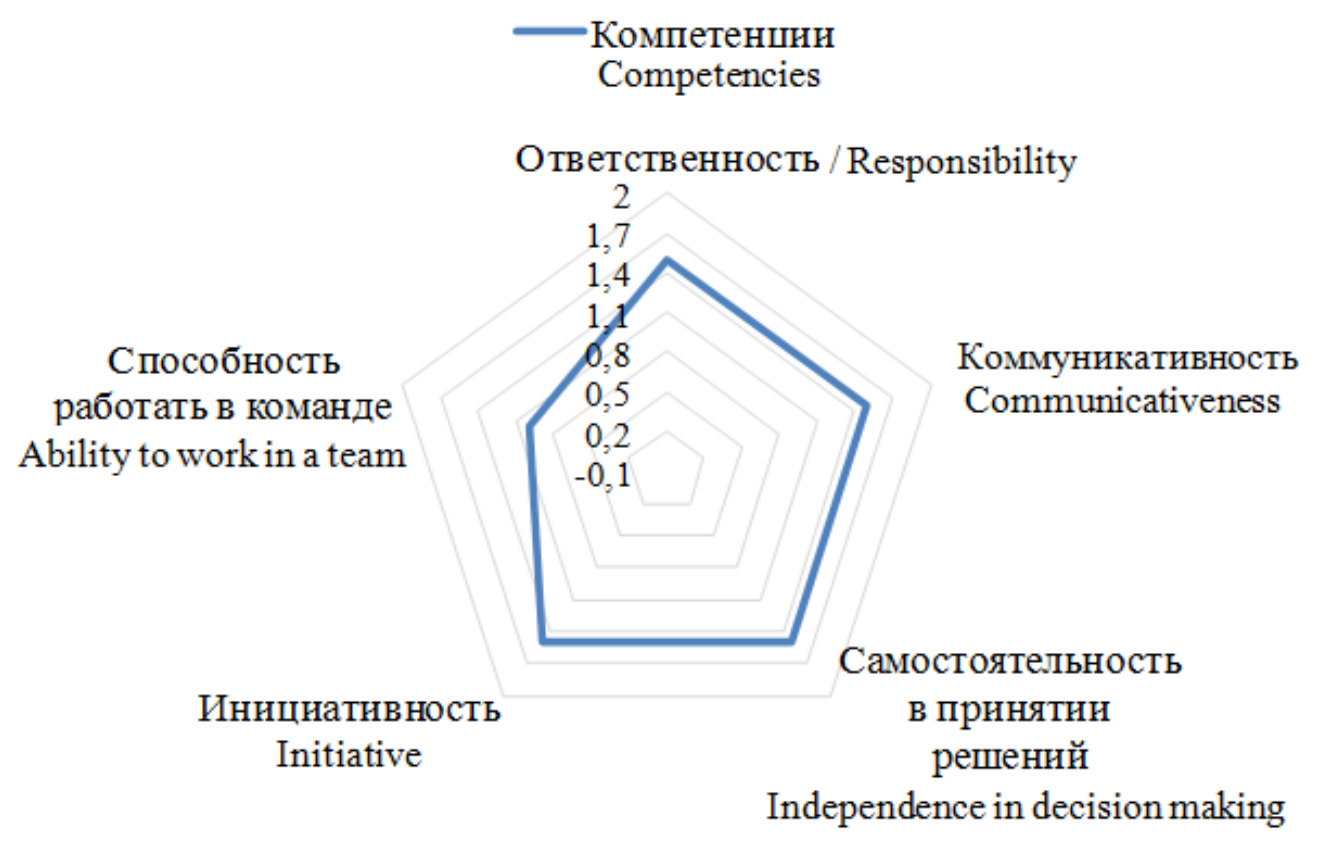

Рисунок. Диаграмма компетенций

Figure. Competence diagram

Игровая механика дополнена ролевой составляющей: ведущий моделирует взаимодействие с клиентом, коллегами, конкурентами, оперативно добавляет оригинальные ситуации, наблюдая за командой.

В тренинге заложены:

- Принцип быстрой связи. Некачественное, нецелевое действие ведет к негативным последствиям, делая связь между поступком и результатом очевидной и прозрачной.

- Реальные кейсы, проблемы, ситуации. Для тренинга разработаны методология проведения и метрики в виде чек-листов для оценки участников тренинга, которые позволяют отследить динамическое развитие навыков внутри команды.

3. После прохождения проекта. Bce soft-навыки динамически изменяются, поэтому важно оценивать, насколько каждый участник прокачал свои компетенции. На обычном собеседовании легко проверяются профессиональные знания сотрудника, а вот личностные выявляются в течение испытательного срока. Прохождение проекта «Академия Умный Мир» дает полную картину менеджеру по персоналу и руководству компании о потенциальных сотрудниках.

\section{Вывод}

Существует дисбаланс между ожиданиями работодателей (связанными, в том числе, с объективными требованиями) и способностями потенциальных программистов, их личностными характеристиками. «Академия Умный Мир» способна разработать и модифицировать программу обучения, которая позволит выделить программистов, у которых имеются склонности к коммуникации, и подготовить адаптированную программу, развивающую данные компетенции. Академия сможет опередить конкурентов, а поскольку данное требование является общим трендом для всего спроса на IT-специалистов, то постепенно и другие программы подготовки адаптируются к формированию коммуникационных компетенций и социализации программистов, что позволит изменить личностный профиль программиста будущего. 


\section{СПИСОК ЛИТЕРАТУРЫ}

1. Академия Умный Мир. URL: https://academy.smartworld.team (дата обращения 19.01.2021).

2. Rubius Academy. URL: https://academy.rubius.com (дата обращения 19.01.2021).

3. Fullstack Development. URL: https://www.fullstack-development.com/en (дата обращения 19.01.2021).

4. Академия Шаг. URL: https://tom.itstep.org (дата обращения 19.01.2021).

5. KODE. URL: https://kode.ru (дата обращения 19.01.2021).

6. Глобальные тенденции 2030: Альтернативные миры. URL: http://eurasiandefence.ru/sites/default/files/DS/Documents/global-trends-2030-rus.pdf (дата обращения 19.01.2021).

7. Неборский Е.В., Тараканов Я.Л. Модель развития коммуникативной компетентности у будущих специалистов IT сферы деятельности // Проблемы современного образования. - 2020. - №. 3. - С. 194-200.

8. Тараканов Я.Л. Коммуникативная компетентность IT специалиста: структура и содержание // Вестник Удмуртского университета. Серия «Философия. Психология. Педагогика». - 2018. - Т. 28. № 3. - С. 351-357.

9. Киселева И.А. Метод проектов и возможности его использования при подготовке специалистовинформатиков // Социально-экономические явления и процессы. - 2011. - № 1-2 (23-24). - С. 341-344.

10. Гладкова М.Н., Ваганова О.И., Смирнова Ж.В. Технология проектного обучения в профессиональном образовании // Проблемы современного педагогического образования. - 2018. - № 58-3. - С. 80-83.

11. Гансуар К., Неретина Е.А., Корокошко Ю.В. Опыт проектно-ориентированного обучения и организации командной работы студентов вуза // Интеграция образования. - 2015. - Т. 19. - № 2 (79). C. $22-30$.

12. Полат Е.С. Метод проектов // Метод проектов в университетском образовании. Сборник науч.-метод. статей. Вып. 6; под общ. ред. М.А. Гусаковского. - Минск: БГУ, 2008. - С. 34-42.

13. Образование для сложного общества. Доклад Global Education Leaders' Partnership Moscow. URL: http://vcht.center/wp-content/uploads/2019/06/Obrazovanie-dlya-slozhnogo-obshhestva.pdf (дата обращения 19.01.2021).

Поступила 23.01.2021 г. 


\title{
FORMATION OF COMMUNICATION SKILLS THROUGH THE INTRODUCTION OF THE SOFT-SKILLS DEVELOPMENT MAP IN THE PROFESSIONAL EDUCATION OF IT SPECIALISTS
}

\author{
Marina V. Ryzhkova1, \\ marybox@inbox.ru \\ Elizaveta 0. Shefer ${ }^{2}$, \\ syo@smartworld.team \\ Anastasia A. Kondratyeva ${ }^{3}$, \\ kondrateva_tusur@mail.ru \\ Ekaterina N. Soboleva 1 , \\ sobolek88@mail.com \\ ${ }^{1}$ National Research Tomsk State University, \\ 36, Lenin avenue, Tomsk, 634050, Russia. \\ 2 National Research Tomsk Polytechnic University, \\ 30, Lenin avenue, Tomsk, 634050, Russia. \\ ${ }^{3}$ Tomsk State University of Control Systems and Radioelectronics, \\ 40, Lenin avenue, Tomsk, 634050, Russia.
}

Marina V. Ryzhkova, Dr. Sc., professor, National Research Tomsk State University.

Elizaveta 0. Shefer, undergraduate student, National Research Tomsk Polytechnic University,.

Anastasia A. Kondratyeva, senior lecturer, Tomsk State University of Control Systems and Radioelectronics.

Ekaterina N. Soboleva, Cand. Sc., associate professor, National Research Tomsk State University.

The relevance of the research lies in the fact that in modern conditions, it is of great importance for employers to minimize costs in the process of adaptation of graduates of the higher professional education system. Often there are communication problems between the employer and the young specialist. This is due to the fact that in the process of learning, students acquire knowledge, skills and abilities, but at the same time they form a certain type of behavior that prevents them from achieving a result with the proper quality, in a certain period of time. It's a result of communication barrier that appears during the adaptation of a young employee in the workplace. The purpose of the research is to identify missing competencies in the professional education for IT specialists and develop competence map in the project «Smart World» Academy (Tomsk IT company «Smart World»). Methods: competitive analysis of professional education for IT specialists, the integral assessments for the analysis of acceleration programs in Tomsk, and the competence map. The study results of employers' needs and trends in the professional education for IT specialists allowed us to draw up competencies map. The main missing competencies in education were soft-skills, especially team work. These competencies are universal for juniors and university graduates. The IT sector and business are interested in development of soft-skills. The competence map will allow Tomsk IT companies selecting employees and influencing their further professional development. And for universities, this map is an indicative profile of a graduate, whose training will increase the demand for an employer. As a result, structural gap between the needs of employers and the professional education for IT specialists will be closed.

Key words: «Smart World» Academy, IT specialist, soft-skills, team training, project based learning. 


\section{REFERENCES}

1. Akademiya Umny Mir [Smart World Academy]. Available at: https://academy.smartworld.team (accessed 19 January 2021).

2. Rubius Academy. Available at: https://academy.rubius.com (accessed 19 January 2021).

3. Fullstack Development. Available at: https://www.fullstack-development.com/en (accessed: 19 January 2021).

4. Akademiya Shag [Academy Step]. Available at: https://tom.itstep.org (accessed 19 January 2021).

5. KODE. Available at: https://kode.ru (accessed 19 January 2021).

6. Globalnye tendentsii 2030: Alternativnye miry [Global Trends 2030: Alternative Worlds]. Available at: http://eurasian-defence.ru/sites/default/files/DS/Documents/global-trends-2030-rus.pdf (accessed 19 January 2021).

7. Neborskiy E.V., Tarakanov Ya.L. Model razvitiya kommunikativnoy kompetentnosti u budushchikh spetsialistov IT sfery deyatelnosti [Development model of communicative competence in future IT]. Problemy sovremennogo obrazovaniya, 2020, no. 3, pp. 194-200. In Rus.

8. Tarakanov Ya.L. Kommunikativnaya kompetentnost IT spetsialista: struktura i soderzhanie [Communicative competence of IT specialist: structure and content]. Vestnik Udmurtskogo universiteta. Seriya «Filosofiya. Psikhologiya. Pedagogika», 2018, vol. 28, no. 3, pp. 351-357.

9. Kiseleva I.A. Metod proektov i vozmozhnosti ego ispolzovaniya pri podgotovke spetsialistov-informatikov [Method of projects and the possibility of its use in training computer specialists]. Sotsialno-ekonomicheskie yavleniya i protsessy, 2011, no. 1-2 (23-24), pp. 341-344.

10. Gladkova M.N., Vaganova O.I., Smirnova Zh.V. Tekhnologiya proektnogo obucheniya v professionalnom obrazovanii [The technology of project-based learning in professional education]. Problemy sovremennogo pedagogicheskogo obrazovaniya, 2018, no. 58-3, pp. 80-83.

11. Gansuar K., Neretina E.A., Korokoshko Yu.V. Opyt proyektno-orientirovannogo obucheniya i organizatsii komandnoy raboty studentov vuza [Experience of project-oriented learning and organisation of teamwork among university students]. Integratsiya obrazovaniya, 2015, vol. 19, no. 2, pp. 22-30.

12. Polat E.S. Metod proektov [Project method]. Metod proektov v universitetskom obrazovanii. Sbornik nauch.-metod. statey. Vyp. 6 [The method of projects in university education. Collection of scientific method. articles. Issue 6]. Ed. by M.A. Gusakovskiy. Minsk, BGU Publ., 2008. 244 p.

13. Obrazovanie dlya slozhnogo obshchestva. Doklad Global Education Leaders' Partnership Moscow [Education for a complex society. Report of Global Education Leaders' Partnership Moscow]. Available at: http://vcht.center/wp-content/uploads/2019/06/Obrazovanie-dlya-slozhnogo-obshhestva.pdf (accessed 19.01.2021).

Received: 23 January 2021. 